active and passive flexion, and the patella was freely movable. On testing for abnormal mobility a slight "give" was experienced in both lateral directions. A calliper splint was provided and worn for six weeks. Seven months from the time of the injury the man began light work. His present condition (11 months after

FIG. 2.

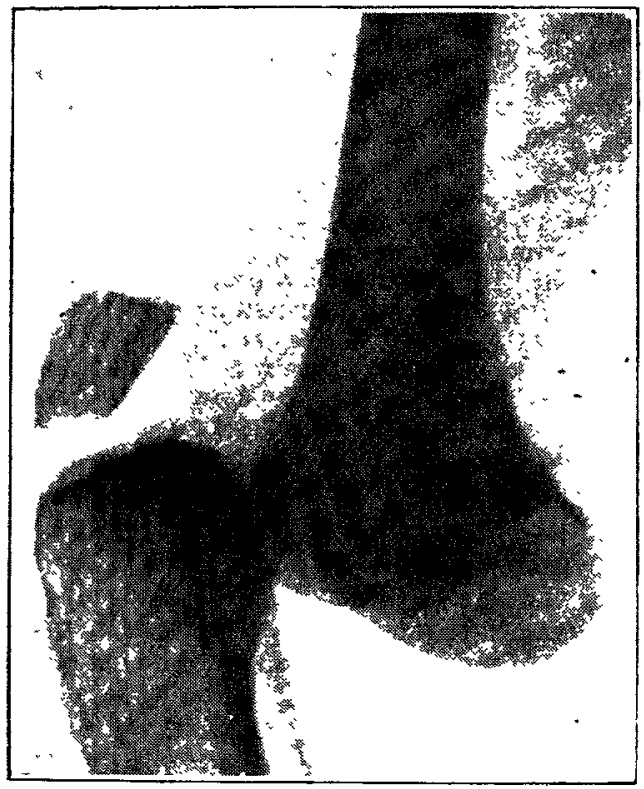

J. E., dislocation of knee-joint. Backward and outward displacement of femur. the accident) is as follows: The kneejoint is pain. les s, a $\mathbf{n} d$ shows a range of 20 degrees of flexion there is definite abnormal lateral mobility of the tibia on the fem ur: this can be elicited by firm mianipulation, but is not evident to $t h e \quad m a n$ during ordinary use of the limb. The man is now working at his old employ ment as a labourer and is carrying out full duties with the ex ception of c $\mathrm{li} \mathrm{m} \mathrm{b}$ i $\mathrm{n} \mathrm{g}$ ladders.

In the two cases described above, as in all complete dislocations of the knee-joint, total rupture of both crucial ligaments with extensive tearing of the capsule, must have occurred. Under conservative treatment, prolonged over a sufficient period, there is every chance of spontaneous repair of these torn structures. This fact has been repeatedly emphasised by Robert Jones, who has seen some extraordinarily good functional results in this type of injury, when continued fixation has been employed. In several of the cases described by this author considerable degrees of motion have been preserved, enabling the individuals to return to full work involving kneeling or to indulge in active sports. The results in my two cases have fallen short of this ideal.

In the case of the young woman $I$ am inclined to regard the period of fixation as too long; as she had gone home to the Midlands there was great delay and trouble in having her readmitted to the hospital; thus we lost valuable time. It is possible that in the course of time there may be a certain degree of stretching of the fibrous mass which fills up the position formerly occupied by the crucial ligaments, with a consequent development of motion in the joint. I have not considered it justifiable to attempt to gain mobility by the use of forcible passive movement, so in this case I look upon the result--viz., firm fibrous ankylosis-as likely to be permanent.

In the second case, after four months' work, there has been a definite increase in the mobility of the injured knee, but I do not anticipate further appreciable increase, as there is very stout resistance to flexion beyond 20 degrees. The man is doing heavy work with comfort, and expresses himself as very satisfied with the result. The accompanying radiograms are probably unique. For their existence and for the notes of the cases on admission to the hospital I am indebted to my former house surgeons, Dr. Booth and Dr. von Mengershausen.

References.-Jones, R.: Injuries to Joints, 1915; Notes on Military Orthopadies, part vi.; Brit. Med. Jour., August 5th, 1916 . Jones and Alwyn - mith: On Rupture of the Crucial Ligaments of the Knee, and on Fractures of the Spine of the Tibia, Brit. Jour. Surgery, July, 1913.

OUR contemporary Knowledge (83, Avenue Chambers, W.C.1), which was founded by the late Richard A. Proctor in 1881 and has for many years disseminated accurate scientific knowledge in a popular form, is to be a quarterly magazine during the war.

\section{THE OPERATIVE TREATMENT OF ABDOMINAL ANEURYSM.}

BY W. I. DE C. WHEELER, F.R.C.S. Ires,

HON. MA.TOR, R.A.V.C.; FON. SURGEON MO THE FORCES IN IRRLAND.

Frve years ago, at the annual meeting of the British Medical Association held in Birmingham, ${ }^{1} \mathrm{I}$ brought before the Association the details of two cases of abdominal aneurysm treated by operation. A year later a third case came under my care, and, like the others, was treated by the introduction of wire into the sac. 1 am now in a position to record the results of operation in the three cases, and in so doing hope to add some information to a subject which has engaged surgical attention for many years.

It is noteworthy that every reported series of cases treated by operation contains a percentage of cures, but the earlier cases dating from the year 1865 showed a discouraging mortality. Osler states that Nature occasionally cures a case. Now and again the physician is able to effect a cure, but he had never seen such a case, and in a few instances he thinks that the surgeon prolongs life or even effects a complete cure. Most of the cases mentioned by Osler lived from a few hours to six months after operation, one surviving. three and a half years.

The recognition of the fact that the introduction of a foreign body into an unhealthy area, such as wire into an aneurysm, requires an aseptic technique of a very special kind, has rendered the results of recent operations more

Frg. 1.

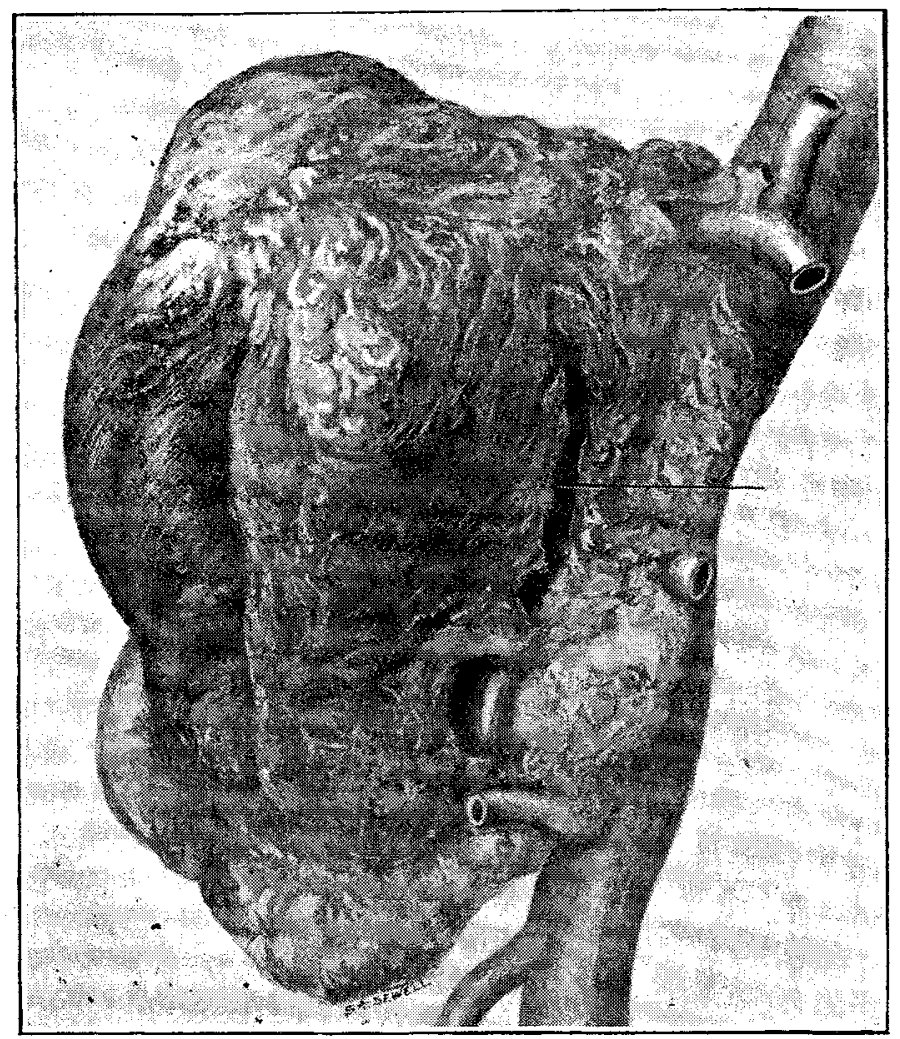

Side view of aneurysm. The line marks the point of rupture. (One-half natural size.)

favourable. In a case of fracture treated by the application of screws and plates acciàental sepsis may be retrieved by the removal of the screws and plate, but once the wire is introduced into the sac of an abdominal aneurysm it is past recall and the surgeon is unable to retrace his steps.

The use of Colt's apparatus ${ }^{2}$ removes the danger caused by the advance of wire from the sac of the aneurysm into the aorta beyond. At least six cases succumbed to this cause in the old days. Rupture of the aorta or of a secondary aneurysmal sac may to some extent be obviated by the rigid application of antispecific treatment, as it is now understood. There is also the possibility of emboli being carried

1 Brit. Med. Jour., 1911 ; Th F IANCE 1911, ii., 507

THE LANCET, 1903, î., 808 . 
from the sac during, or after, the introduction of the wire ; death from this cause, however, has been extremely rare.

The results of my three cases are as follows :-

In the first case of aneurysm of the aorta in the region of the coeliac axis, operated upon in August, 1910, a cage of 150 inches of Colt's wire was introduced. At the time of operation the aneurysm was thin-walled and seemed ready to burst. The patient is still alive and well, at daily work in a brewery. The aneurysm has consolidated and a loud systolic murmur present before operation has disappeared.

The second case, also reported upon in 1910, died in March, 1916, from rupture of the aneurysm, when acting as a stoker in the R.N.R. on board a patrol trawler. A wisp of 105 inches of wire was introduced in this case. A complete post-mortem examination was obtained, the details of which are given below.

The third case was operated upon in 1912 and died about a week after the introduction of the wire from rupture of the aneurysm following intestinal obstruction. A gastroenterostomy was performed in this case as the aneurysm was obstructing the pylorus. The loop of jejunum fixed to the stomach became strangulated by pressure between the abdominal wall and the aneurysm; the consequent vomiting led to rupture of the sac.

In analysing these three cases the first man may be fairly said to be cured. The operation was performed six years ago, at a time when the sac was large and thin-walled. At present the only remaining sign of an aneurysm is a hard mass which transmits the pulsation of the aorta to the abdominal wall. The patient is in good health and performs a full day's work.

The second case lived over five years, and died, while acting as a stoker on board a trawler, from rupture of the sac. From the post-mortem examination it may be fairly claimed that this case was practically cured, and but for the

FIG. 2 .

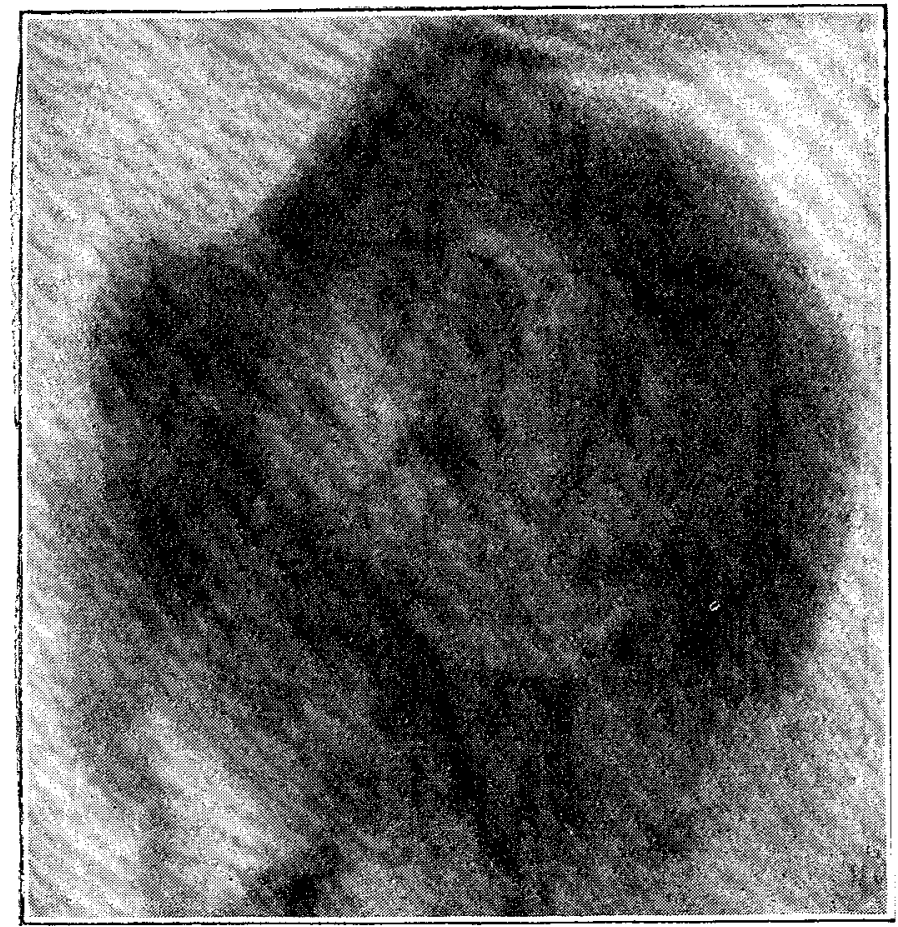

$X$ ray photograph showing Colt's wire within the sac.

fact that the man. was occupied in one of the most strenuous occupations the greatly consolidated aneurysm might never have ruptured.

No conclusions can be drawn from the result of Case 3, the rupture of the aneurysm after the introduction of the wire being obviously due to the vomiting of acute intestinal obstruction.

I am indebted to Surgeon H. E. King Fretz, R.N., for the following post-mortem examination and other notes on Case 2.

The patient, aged 37, a stoker, R.N.R., on one of the patrol trawlers, was admitted into the Naval Hospital on March 12th, 1916. He cumplained of vomiting and severe shooting pain in the right lumbar region simulating renal colic. There was tenderness in the region of the appendix and pain on deep inspiration. He was sweating freely and in a state of collapse. There was a large pulgating tumour which practically occupied the whole of his epigastric region, apparently an aneurysm of the abdominal aorta. His temperature was $97^{\circ} \mathrm{F}$.; pulse 120 , full and regular ; systolic pressure $280 \mathrm{~mm}$., diastolic pressure $120 \mathrm{~mm}$ His urine showed a heavy deposit of urates and a trace of albumin. There was an excellent scar to the left of the mid-line 3 inches long, the result of operation five years ago. A systolic bruit could be heard over the swelling, propagated all over the abdomen and down both femoral arteries. There was a marked diastolic sound in the mitral area and a very accentuated second sound in the aorta. Seven days after admission he died. The swelling continued to pulsate long after respirations had ceased.

At the autopsy it was found that there was a small leak, the hæmorrhage penetrated between the layers of the mesentery, separated them widely apart, and surrounded a large portion of the small intestine. The right kidney was pushed forward. Both kidneys and spleen were normal in size, the right kidney having small granular patches on the surface. The heart was much enlarged. "Now for the aneurysm, I am not exaggerating when I say that the clot formed in it is as hard as a rock, the aneurysm itself is about the size of a full term foetus' head. It appears to me as if there is a secondary dilatation of the aorta below the main swelling and that is where the trouble arose."

I am also indebted to Surgeon King Fretz for the specimen which is faithfully illustrated in Fig. 1, and for the $X$ ray photograph showing the wire in situ (Fig. 2).

It is noteworthy that all three cases presented themselves at hospital complaining of severe pain in the back, and that in none was there any erosion of the vertebræ. It is possible that the intense pain in the back, common to cases of abdominal aneurysm may be due to the stretching of the highly sensitive posterior parietal peritoneum, which is also in these cases subject to a pull at every pulsation of the tumour.

Dublin.

\section{Iftedical Souteties.}

\section{ROYAL SOCIETY OF MEDICINE.}

\section{SECTION OF MEDICINE.}

\section{Exhitition of Autochromes.}

A MEETING of this section was held on March 27th, Dr. T. D. ACLAND being in the chair.

Dr. C. R. Box and Mr. Walter EDMunds exhibited a series of autochromes illustrating the rashes of rubella, measles, scarlet fever, typhoid, cerebro-spinal fever, and pellagra in cases treated at the London Fever Hospital. The autochromes were the products of a three-colour process, the rays of light being transmitted through starch granules, coloured respectively green, orange, and violet, before coming into contact with the customary photographic emulsion. This permitted a very faithful portrayal of the characteristic rashes. The chief drawbacks to the method were the length of exposure necessary with daylight, the intensity of the arc light required when daylight was not used, the impossibility of reproduction, and, for demonstration purposes, the short distance from the screen at which the images must be viewed to appreciate their details.

\section{SECTION OF SURGERY}

Treatment of Severe Infocted Gunshot Injuries of the Shoulder and Elbow Jints.

A MEETING of this section was held on March 14th, Colonel H. J. WARING being in the chair.

Major R. H. JOCELYN SWAN read a paper on the above subject, in which he advocated early excision of the joints with the object of obtaining mobility. The paper is published in full in our present issue.

Mr. KENNETH GOADBY, who had been collaborating with Major Swan, spoke from the bacteriological standpoint. $\mathrm{He}$ showed by lantern slides of the pus the high degree of septicity of such wounds. Besides ordinary pyogenic organisms, anaerobes ( $B$. perfringens, the bacillus of malignant cedema, $B$. Hibner $I X$.) were com. monly present. The streptococci did not seem to be as virulent as those found in civilian practice, such as in post- 